\title{
Important progress and future direction of studies on China's urban agglomerations
}

\author{
FANG Chuanglin \\ Institute of Geographic Sciences and Natural Resources Research, CAS, Beijing 100101, China
}

\begin{abstract}
Urban agglomerations are an inevitable outcome of China's new national industrialization and urbanization reaching relatively advanced stages of development over the past 30 years. In the early 2000s, urban agglomerations became new geographical units for participating in global competition and the international division of labor, and China has spent the past decade promoting them as the main spaces for pushing forward its new form of urbanization. The convening of the first Central Work Conference on Urbanization and the National New-type Urbanization Plan (2014-2020) further defined the status of urban agglomerations as the main players in promoting China's new type of national urbanization. Nevertheless, urban agglomerations remain a weak link in Chinese academia and are in urgent need of study. Only 19 articles on the theme of urban agglomerations were published in the journal Acta Geographica Sinica between 1934 and 2013, accounting for only 0.55\% of all articles written during that period. Not only are there very few, they have also all been published within a relatively short period of time, with the first having been published only 10 years ago. The studies are also concentrated among only a few authors and institutions, and research is aimed at national requirements but is rather divergent. Even so, some studies on urban agglomerations have played a leading role and made important contributions to dictating the overall formation of urban agglomerations nationwide. Specifically, a proposed spatial pattern for urban agglomerations formed the basic framework for the spatial structure of China's urban agglomerations and guided the government to make urban agglomerations the main urban pattern when promoting the new type of urbanization; proposed standards and technologies for identifying the spatial dimensions of urban agglomerations played an important role in defining the scope of national urban agglomerations; a series of studies in the area of urban agglomerations spurred more in-depth and practical studies in the field; and studies on issues related to the formation and growth of urban agglomerations provided warnings on the future selection and development of urban agglomerations. Taking the progress and results of these studies as a foundation, the foci of selecting and developing urban agglomerations in China are as follows: to be problem-oriented and profoundly reflect on and review new problems exposed in the selection and development of urban agglomerations; to concentrate on urban agglomerations and lay importance on the formation of a new " $5+9+6$ " spatial structure for China's urban agglomerations; to rely on urban agglomerations and promote the formation of a new pattern of national urbanization along the main axes highlighted by urban agglom-
\end{abstract}

Received: 2014-12-20 Accepted: 2015-02-08

Foundation: National Natural Science Foundation of China, No.41371177, No.71433008; National Social Science Foundation of China, No.13\&ZD027

Author: Fang Chuanglin, Professor, specialized in urban development and planning. Email: fangcl@igsnrr.ac.cn 
erations; to be guided by national strategic demand and continue to deepen understanding of major scientific issues in the course of the formation and development of urban agglomerations, including studying the resource and environmental effects of high-density urban agglomerations, scientifically examining resource and environmental carrying capacities of high-density urban agglomerations, creating new management systems and government coordination mechanisms for the formation and development of urban agglomerations, studying the establishment of public finance systems and public finance reserve mechanisms for urban agglomerations, and studying and formulating technical specifications for urban agglomeration planning and standards for delineating urban agglomeration boundaries.

Keywords: urban agglomeration; research progress; existing problem; spatial pattern; development direction; China

An urban agglomeration is defined as a group of cities consisting of one or more mega-cities at the core of at least three other large cities within a specific geographical area, all of which rely on a developed transport and communication infrastructure network, have a compact spatial organization, and close economic links, ultimately leading to the formation of conurbations and a high degree of integration. They are the product of advanced industrialization and urbanization as well as of the advanced development of metropolitan areas. From an analysis of urban integration, urban agglomerations break the shackles of the administrative division system and gradually become fully integrated to the extent that planning, urban and rural areas, industries, markets, transport, information, finances, science and technology, ecological conservation and environmental protection all become interlinked in economic and interest-based communities (Fang et al., 2010). Specifically, they consist of 10 major communities: planning communities, economic communities, urban and rural communities, transport communities, information communities, finance communities, market communities, innovation communities, environmental communities, and ecological communities. From an analysis of highly integrated urban agglomerations, six major areas of integration require focus and should be promoted when developing urban agglomerations: integration of regional industrial layout, urban and rural planning and development, regional market development, infrastructure development, environmental and ecological development, and social development and social security system development.

\section{Promoting urban agglomerations as the main spaces for pushing for- ward the new type of urbanization over the past decade in China}

\subsection{Economic globalization has made urban agglomerations the new geographical units for participating in global competition and the international division of labor}

With the acceleration of economic globalization and development of urbanization, inter-city competition is not only reflected in competition between individual cities, but increasingly reflected in competition between urban agglomerations and groups of cities with core cities at each of their centers. Indeed, urban agglomerations with large cities as their core have already become a globally significant urban-regional development model and spatial combination model. Only with the existence of an urban agglomeration is it possible to have a sufficient industry cluster and economies of scale to participate in global urban competition 
and cooperation, and form strong economic communities and communities with a shared destiny to meet the challenges of globalization (Yao et al., 2006). It is apparent that urban agglomerations are all-new geographical units for participating in global competition and the international division of labor and will determine the new pattern of world politics and economics in the 21st century.

\subsection{The national plan for major function-oriented zones viewed urban agglomera- tions as key development zones and optimal development zones}

The National Plan for Major Function-Oriented Zones approved by the State Council divided national land space into optimal development zones, key development zones, restricted development zones, and prohibited development zones for the first time. A comparative analysis of the spatial distribution of China's urban agglomerations shows that the vast majority is located in key and optimal development zones, which indicates that urban agglomerations occupy a very important position in main functional zones. ${ }^{1}$

\subsection{Central Work Conference on urbanization viewed urban agglomerations as the main entities promoting the new form of urbanization}

The Central Work Conference on Urbanization held in December 2012 first proposed the six major tasks for the new type of urbanization. The fourth of these six major tasks is to optimize the layout and form of urbanization. The work conference also proposed for the first time that urban agglomerations are mainly responsible for promoting the new form of urbanization, and it suggested that, in addition to continuing to optimize the development of the Beijing-Tianjin-Hebei, Yangtze River Delta, and Pearl River Delta major national-level urban agglomerations and striving to build world urban agglomerations that are internationally competitive, China should gradually develop several urban agglomerations in western and northeastern regions (which will become important growth poles for developing those regions) that meet the necessary conditions by relying on market forces and national planning guidance.

\subsection{China's past two national five-year plans considered urban agglomerations the main entities in driving the new type of urbanization}

China's 11th Five-Year Plan (2006-2010) clearly stated, “To make urban agglomerations the main entity for driving urbanization, we must gradually form an efficient, coordinated, and sustainable urban spatial pattern with the Beijing-Guangzhou and Beijing-Harbin railway lines forming the vertical axes, the Yangtze River and the Longhai railway forming the horizontal axes, with several urban agglomerations as the main players and other cities and small towns distributed around them and with permanent arable land and ecological function zones in between."

The 12th Five-Year Plan (2011-2015) further clarified the idea: "In actively yet prudently promoting urbanization along the path of urbanization with Chinese characteristics and in accordance with the objective law governing urban development, we will gradually form urban agglomerations with a major radiation effect by taking large cities as the crux and

\footnotetext{
${ }^{1}$ State Council of the People’s Republic of China, National Plan for Major Function-Oriented Zones-Building an Efficient, Coordinated, and Sustainable National Spatial Development Pattern, June 2011
} 
small and middle-sized cities as the focus, so that we will be able to promote coordinated development between small towns and large, medium-sized, and small cities (Fang, 2012). ${ }^{1}$

\subsection{Reports of the 17th and 18th National Congresses of the CPC identified urban agglomerations as new economic growth poles}

The report of the 17th National Congress of the Communist Party of China (CPC), held in October 2007, pointed out, "To take the path of urbanization with Chinese characteristics, we must focus on increasing the overall carrying capacity of cities, form urban agglomerations with a significant radiation effect by relying on megacities, and cultivate new economic growth poles."

The report of the 18th National Congress of the CPC, held in September 2012, also pointed out the need to "continue to implement the overall strategy for regional development, scientifically plan the size and layout of urban agglomerations, enhance the industrial development, public services, job creating and population clustering functions of small and medium-sized cities as well as small towns, accelerate reform of the household registration system, allow people who have left agriculture for other work to become urban residents in an orderly manner, and strive to achieve complete coverage of basic public services for resident populations of cities."2

\subsection{Central Economic Work Conferences in 2012-2013 proposed rationally distrib- uting urban agglomerations}

Following China's 11th and 12th five-year plans identifying urban agglomerations as the main spatial forms for promoting urbanization, the Central Economic Work Conference held in 2012 proposed the need to promote their development based on the functional orientation determined by the National Plan for Major Function-Oriented Zones so as to scientifically guide their development. The Central Economic Work Conference in December 2013 went on to suggest the need to build a scientific and rational urban pattern, with a scientific layout of small and medium-sized cities, small towns, and urban agglomerations that is closely linked to regional economic development and industrial layout, and suited to local resource and environmental carrying capacities.

\subsection{The National New-type Urbanization Plan (2014-2020) identified urban agglom- erations as the main entities promoting the new type of urbanization in China}

On March 16, 2014, the State Council approved the implementation of the National New-type Urbanization Plan (2014-2020), which proposed putting people at the heart of urbanization and allowing people who have left agriculture for other work to become urban residents in an orderly manner; making urban agglomerations the main urban forms and promoting coordinated development between small towns and small and medium-sized cities; and taking the path toward a new type of urbanization with Chinese characteristics by being people-oriented, simultaneously promoting industrialization, informationization, ur-

\footnotetext{
1 State Council of the People's Republic of China, The Twelfth Five-Year Plan for National Economic and Social Development of the People's Republic of China, 2011

$2 \mathrm{Hu}$ Jintao, Unswervingly Advance Along the Road of Socialism with Chinese Characteristics to Build a Moderately Prosperous Society in All Respects, Report delivered at the 18th National Congress of the Communist Party of China, September 2012
} 
banization, and agricultural modernization, optimizing the layout of cities, and promoting a conservation culture and cultural continuity. ${ }^{1}$

It can be seen that as China's urbanization and industrialization have accelerated, urban agglomerations have become the most dynamic and promising core areas for economic development today and in the future. They also play the role of strategic anchors, growth poles, and core nodes in the national productivity distribution pattern and layout, bring together and facilitate various regional and national flows of factors of production, and dominate the lifeblood of China's economic development. According to incomplete evidence, urban agglomerations accounted for $25 \%$ of China's total urban areas in 2012, but $62 \%$ of the country's population, $80 \%$ of economic output, $70 \%$ of fixed asset investment, $76 \%$ of retail sales of consumer goods, $85 \%$ of higher education students, $92 \%$ of cell phone users, $98 \%$ of foreign investment, and $48 \%$ of food consumption, making them the most dynamic and promising regions within China's major economic zones today and in the future (Fang et al., 2011). In the process of promoting the new form of urbanization, it is essential to scientifically and rationally develop a hierarchy of national-level urban agglomerations, regional urban agglomerations, and local urban agglomerations.

\section{Research on urban agglomerations published in Acta Geographica Sinica in the past 80 years}

Urban agglomerations are an inevitable outcome of the advanced development of China's industrialization and urbanization. Although the importance of promoting urbanization is fully recognized by political and academic circles, due to their late development - less than 35 years ago in China, which is around 80 years later than Western countries - the basic connotations, spatial delineation, degree of development, and construction foci of urban agglomerations in China are less certain and more contentious. This, in turn, has set off a wave of academic research into urban agglomerations in recent years. Below is a list of papers on urban agglomerations published in the Chinese journal Acta Geographica Sinica in the past 80 years.

\subsection{A small number of articles published in a short space of time}

In the 80 years from 1934 to 2013, Acta Geographica Sinica published a total of 3460 articles. Only 19, or $0.55 \%$, contained the key terms "urban economic zone” or "urban agglomeration" (see Table 1). Apart from there being few such studies, it is also notable that all were written in less than 25 years, since 1991. In 1991, Gu Chaolin first conducted a study on Chinese urban economic zoning (Gu, 1991). If it is accepted that "urban economic zone" is an earlier academic term for "urban agglomeration," then this can be considered the first time the concept of urban agglomeration appeared in academic research. If one does not agree that these terms are consistent, the first article on the topic of urban agglomerations would be Fang Chuanglin's research on spatial differentiation of the structural systems of Chinese urban agglomerations (Fang, 2005). If this is considered the first such paper, then there is an even shorter history - less than 10 years - of published academic papers on the

\footnotetext{
1 State Council of the People's Republic of China, National New-type Urbanization Plan (2014-2020), March 2014
} 
Table 1 Statistical chart of academic papers related to urban agglomerations and urban economic zones in the past 80 years

\begin{tabular}{|c|c|c|c|c|c|c|c|}
\hline No. & Author & Title & Institution of main author & Year & Vol. & Iss. & Page \\
\hline 1 & Gu Chaolin & $\begin{array}{l}\text { A preliminary study of Chinese } \\
\text { urban economic zoning }\end{array}$ & $\begin{array}{l}\text { National Planning Commission } \\
\text { Geographic Institute, CAS }\end{array}$ & 1991 & 46 & 2 & $129-141$ \\
\hline 2 & $\begin{array}{l}\text { Xue Fengxuan, } \\
\text { Yang Chun }\end{array}$ & $\begin{array}{l}\text { The transborder economic region } \\
\text { of Hong Kong-Shenzhen }\end{array}$ & $\begin{array}{l}\text { Department of Geography and } \\
\text { Geology, University of Hong Kong }\end{array}$ & 1997 & 52 & $\mathrm{~S}$ & $016-027$ \\
\hline 3 & $\begin{array}{l}\text { Yao Shimou, } \\
\text { Chen Shuang }\end{array}$ & $\begin{array}{l}\text { Trends in urban spatial evolution } \\
\text { in the Yangtze River Delta }\end{array}$ & $\begin{array}{l}\text { Nanjing Institute of Geography } \\
\text { and Limnology, CAS }\end{array}$ & 1998 & 53 & $\mathrm{~S}$ & $001-010$ \\
\hline 4 & $\begin{array}{l}\text { Zhou Yixing, } \\
\text { Zhang Li }\end{array}$ & $\begin{array}{l}\text { China's urban economic region } \\
\text { in the open context }\end{array}$ & $\begin{array}{l}\text { Geographic Sciences Research } \\
\text { Center, Peking University }\end{array}$ & 2003 & 58 & 2 & $271-284$ \\
\hline 5 & $\begin{array}{l}\text { Ma Xiaodong, } \\
\text { Ma Ronghua, } \\
\text { Xu Jiangang }\end{array}$ & $\begin{array}{l}\text { Spatial structure of cities and } \\
\text { towns with ESDA-GIS frame- } \\
\text { work }\end{array}$ & $\begin{array}{l}\text { Urban and Resource Department, } \\
\text { Nanjing University }\end{array}$ & 2004 & 59 & 6 & 1048-1057 \\
\hline 6 & $\begin{array}{l}\text { Wang Zhixian, } \\
\text { Yu Xiaogan, } \\
\text { Xu Kefeng }\end{array}$ & $\begin{array}{l}\text { Sustainable development trends } \\
\text { and countermeasures in the } \\
\text { Yangtze River Delta }\end{array}$ & $\begin{array}{l}\text { Nanjing Institute of Geography } \\
\text { and Limnology, CAS }\end{array}$ & 2005 & 60 & 3 & $381-391$ \\
\hline 7 & $\begin{array}{l}\text { Fang Chuanglin, } \\
\text { Song Jitao, } \\
\text { Zhang Qiang, } \\
\text { et al. }\end{array}$ & $\begin{array}{l}\text { The formation, development and } \\
\text { spatial heterogeneity patterns for } \\
\text { the structures system of urban } \\
\text { agglomerations }\end{array}$ & $\begin{array}{l}\text { Institute of Geographic Sciences } \\
\text { and Natural Resources Research, } \\
\text { CAS }\end{array}$ & 2005 & 60 & 5 & $827-840$ \\
\hline 8 & $\begin{array}{l}\text { Song Jitao, } \\
\text { Fang Chuanglin, } \\
\text { Song Dunjiang }\end{array}$ & $\begin{array}{l}\text { Stability analysis of the spatial } \\
\text { structure of Chinese urban ag- } \\
\text { glomeration }\end{array}$ & $\begin{array}{l}\text { Institute of Geographic Sciences } \\
\text { and Natural Resources Research, } \\
\text { CAS }\end{array}$ & 2006 & 61 & 12 & $1311-1325$ \\
\hline 9 & $\begin{array}{l}\text { Fang Chuanglin, } \\
\text { Qi Weifeng, } \\
\text { Song Jitao }\end{array}$ & $\begin{array}{l}\text { Comprehensive measurement } \\
\text { analysis of the compactness of } \\
\text { Chinese urban agglomeration }\end{array}$ & $\begin{array}{l}\text { Institute of Geographic Sciences } \\
\text { and Natural Resources Research, } \\
\text { CAS }\end{array}$ & 2008 & 63 & 10 & $1011-1021$ \\
\hline 10 & $\begin{array}{l}\text { Sun Fenghua, } \\
\text { Wei Xiao, } \\
\text { Liu Yuqiao }\end{array}$ & $\begin{array}{l}\text { Core competitiveness of the } \\
\text { logistics industry in the Shan- } \\
\text { dong Peninsula urban agglom- } \\
\text { erations }\end{array}$ & $\begin{array}{l}\text { School of Traffic and Transporta- } \\
\text { tion, Ludong University }\end{array}$ & 2008 & 63 & 10 & $1108-1118$ \\
\hline 11 & $\begin{array}{l}\text { Wang Kaiyong, } \\
\text { Chen Tian }\end{array}$ & $\begin{array}{l}\text { The classification and analysis of } \\
\text { areal topology in extended metro- } \\
\text { politan area of Pearl River Delta }\end{array}$ & $\begin{array}{l}\text { Institute of Geographic Sciences } \\
\text { and Natural Resources Research, } \\
\text { CAS }\end{array}$ & 2008 & 63 & 8 & $820-828$ \\
\hline 12 & $\begin{array}{l}\text { Chen Hao, } \\
\text { Lu Lin, } \\
\text { Zheng Shanting }\end{array}$ & $\begin{array}{l}\text { The spatial network structure of } \\
\text { the tourism destinations in urban } \\
\text { agglomerations based on tourist } \\
\text { flow: A case study of the Pearl } \\
\text { River Delta }\end{array}$ & $\begin{array}{l}\text { College of Land Resources and } \\
\text { Tourism, Anhui Normal Univer- } \\
\text { sity }\end{array}$ & 2011 & 66 & 2 & $257-266$ \\
\hline 13 & $\begin{array}{l}\text { Zhang Qian, } \\
\text { Hu Yunfeng, } \\
\text { Liu Jiyuan }\end{array}$ & $\begin{array}{l}\text { Identification of urban clusters in } \\
\text { China based on assessment of } \\
\text { transportation accessibility and } \\
\text { socio-economic indicators }\end{array}$ & $\begin{array}{l}\text { Institute of Geographic Sciences } \\
\text { and Natural Resources Research, } \\
\text { CAS }\end{array}$ & 2011 & 66 & 6 & $761-770$ \\
\hline 14 & $\begin{array}{l}\text { Fang Chuanglin, } \\
\text { Guan Xingliang }\end{array}$ & $\begin{array}{l}\text { Integrated measurement and } \\
\text { spatial differentiation of the } \\
\text { input-output efficiency of Chi- } \\
\text { nese urban agglomerations }\end{array}$ & $\begin{array}{l}\text { Institute of Geographic Sciences } \\
\text { and Natural Resources Research, } \\
\text { CAS }\end{array}$ & 2011 & 66 & 8 & $1011-1022$ \\
\hline 15 & $\begin{array}{l}\text { Chen Hao, } \\
\text { Lu Lin, } \\
\text { Zheng Shanting }\end{array}$ & $\begin{array}{l}\text { Evolution of travel spatial pat- } \\
\text { terns in the Pearl River Delta } \\
\text { urban agglomeration }\end{array}$ & $\begin{array}{l}\text { College of Land Resources and } \\
\text { Tourism, Anhui Normal Univer- } \\
\text { sity }\end{array}$ & 2011 & 66 & 10 & $1427-1437$ \\
\hline 16 & $\begin{array}{l}\text { Kuang Wenhui, } \\
\text { Liu Jiyuan, } \\
\text { Liu Dengsheng }\end{array}$ & $\begin{array}{l}\text { Beijing-Tianjin-Tangshan urban } \\
\text { agglomeration impervious sur- } \\
\text { face growth and the environ- } \\
\text { mental effects on water }\end{array}$ & $\begin{array}{l}\text { Institute of Geographic Sciences } \\
\text { and Natural Resources Research, } \\
\text { CAS }\end{array}$ & 2011 & 66 & 11 & 1486-1496 \\
\hline 17 & $\begin{array}{l}\text { Liu Hui, } \\
\text { Shen Yuming, } \\
\text { Liu Kun }\end{array}$ & $\begin{array}{l}\text { The financial services industry } \\
\text { development level and spatial } \\
\text { pattern of urban agglomeration } \\
\text { in China }\end{array}$ & $\begin{array}{l}\text { College of Resources, Environ- } \\
\text { ment and Tourism, Capital Nor- } \\
\text { mal University }\end{array}$ & 2013 & 68 & 2 & 186-198 \\
\hline 18 & $\begin{array}{l}\text { Wang Li, } \\
\text { Deng Yu, } \\
\text { Niu Wenyuan }\end{array}$ & $\begin{array}{l}\text { The definition and identification } \\
\text { of urban agglomerations }\end{array}$ & $\begin{array}{l}\text { Institute of Spatial Planning and } \\
\text { Regional Economy, National } \\
\text { Development and Reform Com- } \\
\text { mission }\end{array}$ & 2013 & 68 & 8 & 1059-1070 \\
\hline 19 & $\begin{array}{l}\text { Xiong Ying, } \\
\text { Li Jingzhi, } \\
\text { Jiang Dingling }\end{array}$ & $\begin{array}{l}\text { Optimized decision-making of } \\
\text { water resources supply and } \\
\text { demand system in Chang- } \\
\text { sha-Zhuzhou-Xiangtan urban } \\
\text { agglomeration based on the } \\
\text { analog simulation }\end{array}$ & $\begin{array}{l}\text { Resources and Environment } \\
\text { Department, Changsha Univer- } \\
\text { sity of Science and Technology }\end{array}$ & 2013 & 68 & 9 & 1225-1239 \\
\hline
\end{tabular}


subject of urban agglomerations in Acta Geographica Sinica.

\subsection{Focus of research units and author groups}

From an analysis of research institutions from which research results on urban agglomerations have arisen, one finds that the Institute of Geographic Sciences and Natural Resources Research of the Chinese Academy of Sciences (CAS) is responsible for the most research in this area with eight papers, or $42.1 \%$ of studies. Second is the Nanjing Institute of Geography and Limnology of the CAS with two papers. Hong Kong University, Peking University, Nanjing University, Ludong University, Changsha University of Science and Technology, the Institute of Land Development and Regional Economics of the National Development and Reform Commission, and Capital Normal University have all published one article each. From this it can be seen that the team at the Institute of Geographic Sciences and Natural Resources Research of the CAS has published the most articles on urban agglomerations. It is also the strongest research team with the greatest influence on the formation and development of urban agglomerations.

From an analysis of the authors, one finds that the author who has published the most articles on urban agglomerations in Acta Geographica Sinica is Fang Chuanglin from the Institute of Geographic Sciences and Natural Resources Research of the CAS with four articles. Second is Chen Hao of the College of Land Resources and Tourism of Anhui Normal University with two, while Gu Chaolin, Zhou Yixing, Xue Fengxuan, Yao Shimou, Zhang Qian, Sun Fenghua, Ma Xiaodong, Kuang Wenhui, Liu Hui, Wang Li, Xiong Ying, Wang Zhixian and Wang Kaiyong have all published one article each.

\subsection{Targeting national requirements and diffusing research content}

From a spatial scale analysis of the research content, we can see that it includes urban agglomerations with different spatial scales and different developmental levels across the country, such as the Yangtze River Delta, Pearl River Delta, Shandong Peninsula, Wuhan, Central Plains, and Changsha-Zhuzhou-Xiangtan urban agglomerations.

From a specific analysis of the research content, one finds that the 19 articles were academic papers on topics related to urban economic zones, basic connotations of urban agglomeration, determining boundaries of urban agglomeration (Fang, 2009), the formation of dynamic mechanisms for the development of urban agglomerations (Wang and Fang, 2011; Ma et al., 2004), the spatial structure of urban agglomeration (Yan and Chen, 1998; Wang et al., 2005), the degree of development of urban agglomeration, the degree of compactness of urban agglomeration (Song et al., 2006), degree of stability of urban agglomeration (Fang et al., 2008), the input-output efficiency of urban agglomeration (Fang and Guan, 2011), the resource and environmental carrying capacities of urban agglomeration (Fang and Liu, 2010), the ecological and environmental effects of urban agglomeration (Fang and Lin, 2010), industrial clustering in urban agglomeration (Lin and Fang, 2010), the logistics industry and urban agglomeration (Sun et al., 2008), urban agglomeration travel networks (Chen et al., 2011a, 2011b), the sustainable development of urban agglomeration (Fang, 2010; Guan et al., 2012), and safeguard mechanisms for urban agglomerations (Wang and Chen, 2008; Fang and Zhang, 2011). This content is basically consistent with requirements for developing a national urbanization development strategy, and has therefore played an 
important role in leading the overall formation and development of China's urban agglomerations.

\section{Leading role and contributions of research in the overall formation of China's urban agglomerations}

\subsection{Proposed spatial pattern of urban agglomerations forms basic framework of na- tional urban agglomeration spatial structure}

In 1991, Professor Gu Chaolin (1991) used 33 indicators to conduct a comprehensive evaluation of the strength of 434 cities in China and proposed the idea of China having an urban economic zoning system consisting of two major economic development zones, three economic development axes, nine major urban economic zones, and 33 second-tier urban economic zones. These included the proposed economic zones of Shenyang, Beijing-Tianjin, Xi'an, Shanghai, Wuhan, Chongqing, Guangzhou, Urumqi, and Lhasa as a theoretical basis for the future national urban agglomeration spatial pattern.

In 2003, Professor Zhou Yixing used empirical methods to conduct a new study on China's urban economic zones from the perspective of reform and opening up. Based on a hierarchy of urban centers, the study defined the Beijing-Tianjin-Tangshan, Yangtze River Delta, and Pearl River Delta national economic core areas, and by using a flow and directional analysis of the flow of goods in foreign trade, railway passenger flows, migration flows, and mail flows it divided China's economic regions into three first-tier urban economic zones, namely the northern region, northeast region, and southern region, and 11 second-tier zones (Zhou and Zhang, 2003). The 11 second-tier zones, consisting of the Beijing-Tianjin-Tangshan core zone, Yangtze River Delta core zone, Pearl River Delta core zone, Liaoning central and southern core zone, Sichuan Basin core zone, central Shaanxi-Lanzhou core zone, northern Tianshan Mountains core zone, Shandong Peninsula core zone, Wuhan core zone, and southeast Fujian core zone, were identified as having played a positive and guiding role in the formation of the spatial structure of today's national urban agglomerations.

In 2005, Professor Fang Chuanglin et al. (2005) formally introduced the idea of urban agglomeration and stated that China's urban agglomeration system is made up of 28 clusters of varying sizes, scales, and development levels, all of which are still in the developmental prototype stage. On the basis of the results of an index model on the degree of development of China's urban agglomerations, Fang Chuanglin divided them into three tiers. First-tier urban agglomerations refer to the Yangtze River Delta, Pearl River Delta, and Beijing-Tianjin-Hebei urban agglomerations; second-tier urban agglomerations refer to the Shandong Peninsula, Chengdu, Wuhan, and eight other urban agglomerations; third-tier urban agglomerations refer to the central Yunnan, northern Tianshan Mountains, and 12 other urban agglomerations. Further analysis showed that China's urban agglomerations had a low development level overall and differences in development level were significant. These differences had a certain degree of rationality and showed that development occurs in stages, there is regularity of spatial variation, heterogeneity of internal concentration, and clear differentiation. The results of this study later became the basic framework for the spatial struc- 
ture of China's urban agglomerations.

In 2011, an urban agglomeration research team from the Institute of Geographic Sciences and Natural Resources Research of the CAS led by Fang Chuanglin published the first Report on Urban Agglomeration Development in China (Fang, 2011), which proposed seven quantitative criteria for evaluating the formation and development of urban agglomerations. These quantitative criteria were then used to further refine the spatial pattern of 28 urban agglomerations identified in 2005 down to 23 urban agglomerations (see Figure 1), consisting of 23 urban agglomerations with government-led construction, 15 of which met development criteria, and eight of which did not. This spatial pattern was fully affirmed by the National Development and Reform Commission, and the research results were directly incorporated into the National New-type Urbanization Plan (2014-2020) as an important section on optimizing urbanization plans and layout.

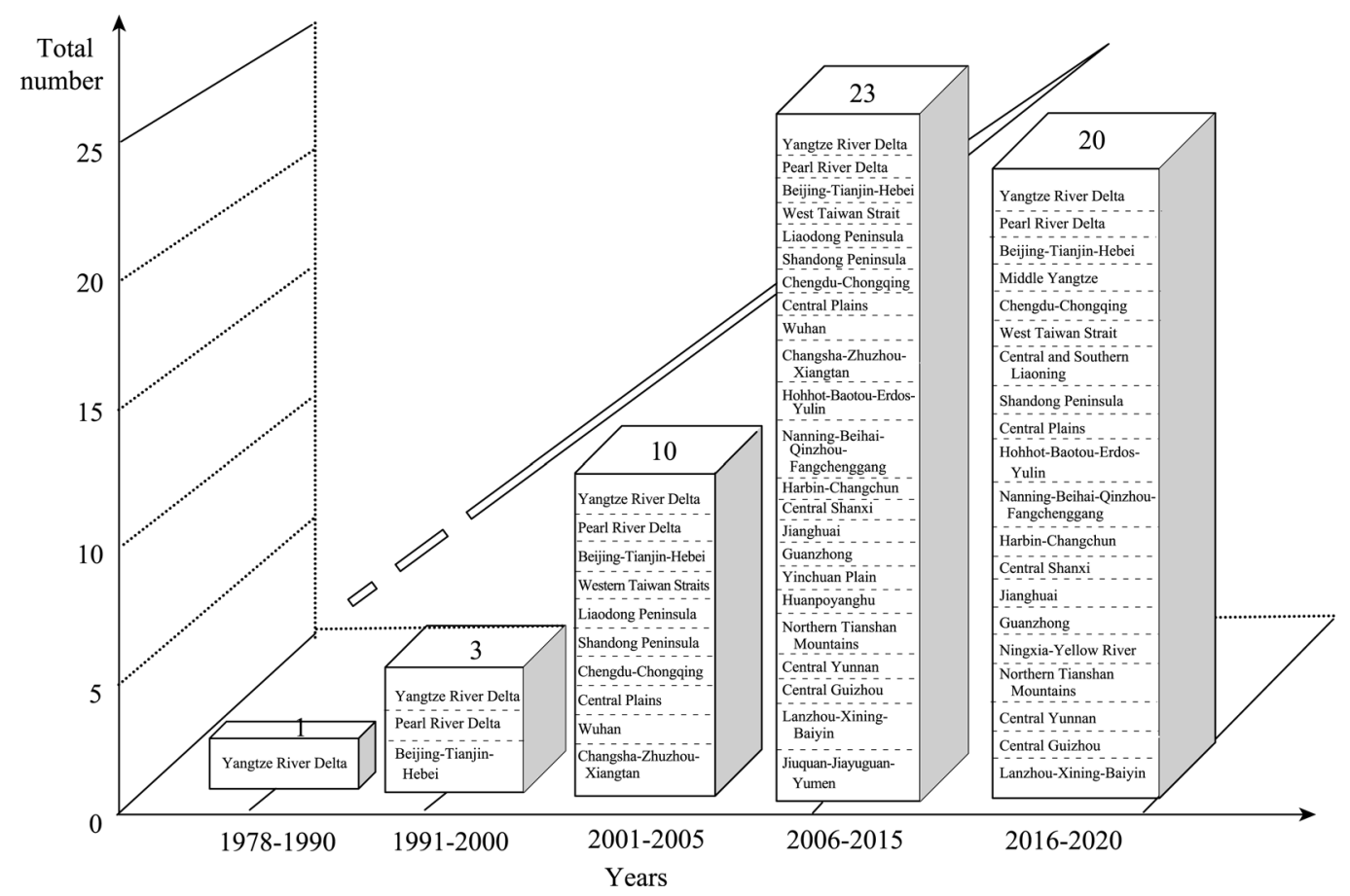

Figure 1 Numbers of urban agglomerations in China

In 2013, the "15+8" national urban agglomeration spatial pattern was refined following the formulation and implementation of the National Plan for Major Function-Oriented Zones and the National New-type Urbanization Plan to become the new " $5+9+6$ " urban agglomeration spatial structure, consisting of the construction of five national-level, nine regional-level, and six local urban agglomerations. This urban agglomeration spatial structure was formally incorporated into state planning.

\subsection{Guiding the national plan for new-type urbanization to designate urban agglom- eration as the main entities for promoting new-type urbanization}

It has taken the continuous accumulation of research, holding of various forums, and transfer of basic knowledge to decision-making departments in order to influence the views of rele- 
vant state organs toward urban agglomerations. Initially, research results on urban agglomerations published in Acta Geographica Sinica were not readily accepted by the academic community and state organs. Rather, further research projects were commissioned before they were gradually accepted and eventually fully accepted and incorporated into the national Eleventh Five-Year Plan report, Twelfth Five-Year Plan report, report of the Central Work Conference on Urbanization, 17th Party Congress report, 18th Party Congress report, and finally the National New-type Urbanization Plan (2014-2020). This process of accumulating scientific knowledge on urban agglomerations quickly elevated their status within academic and political circles until the Central Work Conference on Urbanization in December 2013 and the State Council implemented the National New-type Urbanization Plan (2014-2020) in March 2014, which both promoted urban agglomerations as the main entities for promoting new-type urbanization. They also proposed building a new pattern of urbanization consisting of coordinated development between urban agglomerations and large, small, and medium-sized cities, as well as small towns, that follows a path of urbanization with Chinese characteristics, meaning that it is people-oriented, simultaneously promotes industrialization, informationization, urbanization, and agricultural modernization, optimizes the layout of cities, and promotes a conservation culture and cultural continuity. The goal is to build urban agglomerations into basic units for China's participation in international economic cooperation and competition; build national economic development core zones, different types of national sustainable development demonstration areas, and pilot areas for opening up to international competition; further strengthen the space and position of urban agglomerations in promoting national urbanization and their central position in national economic and social development; and make contributions to building world-class urban agglomerations.

\subsection{Important role of standards and technical processes for determining spatial boundaries of urban agglomerations}

On the basis of Fang Chuanglin et al.'s research (2005), an analysis of the formation and development experience of the expansion of spatial boundaries of urban agglomerations proposed seven quantitative criteria for identifying the spatial boundaries of urban agglomerations: an urban agglomeration must contain at least three metropolitan areas or large cities, including at least one megalopolis or megacity with a population greater than 5 million and have a total population of no less than 20 million, a level of urbanization above $50 \%$, per capita GDP of more than US\$10,000 and economic density greater than RMB 5 million yuan $/ \mathrm{km}^{2}$, more than 30\% outward-oriented economy, basic formation of highly developed and integrated transport channels with access to economic zones within half an hour, one hour, and two hours, a non-agricultural output value ratio that exceeds 70\%, a core city GDP concentration of less than $45 \%$, and inter-provincial urban functions.

Although not scientifically rational, these criteria have quantitatively solved the key problem of previously having no standards by which to select urban agglomerations, and they have played an important role in achieving a more scientific understanding of urban agglomerations and rationally defining their spatial boundaries. At the same time, a regional combined model and geo-information technology were used to create an urban agglomeration identification system and propose a technical process for quickly identifying and zoning 
urban agglomerations with the help of GIS technology to summarize transport, population, and economic attributes, thereby providing technical support for delimiting the boundaries of urban agglomerations more scientifically and rationally (Zhang et al., 2011; Wang et al., 2013).

\subsection{Proposed series of research fields makes urban agglomeration research more in-depth and practical}

A proposed theory on the sustainable development and dynamic mechanisms of urban agglomerations laid a scientific theoretical foundation for formulating a national urban agglomeration development plan. Research results on the degree of development, compactness, stability, resource and environmental carrying capacities, and input-output efficiency of urban agglomeration provided a quantitative scientific decision-making basis for determining various levels and spatial scales of sustainable development among urban agglomerations. A proposed classification scheme for different degrees of development of China's urban agglomerations provided a differentiated development model and policy support measures for the state to develop urban agglomerations in accordance with local conditions. Proposed industrial development research results on models for developing industry clusters, urban agglomeration logistics networks, and travel networks laid a solid industrial basis for promoting the construction of modern industry cluster zones and high-end industry cluster bases in urban agglomerations and building urban agglomerations into ecological, innovative, low-carbon, compact, and smart urban agglomerations. On the one hand, all of these research findings laid a solid early research foundation for more in-depth research on urban agglomerations in China, and on the other hand, provided a reference base for the formulation of national and regional-level urban agglomerations, thereby greatly encouraging research on urban agglomerations to become more in-depth and practical.

\subsection{Problems identified in the formation and development of urban agglomerations serve as a warning for their future selection and development}

The 19 research papers on the topic of urban agglomerations identified a series of problems related to their formation and development, which mainly fall into the following three main areas: first, excessive government intervention, overestimates of development prospects, negative effects from excessive urban density, and an excessive development gap; second, blindly following national strategies and constructing national pilot areas with little regard for local conditions, desperately attempting to expand power and strength in spite of the ecological red line and triggering massive city-building movements, competing through redundant construction, the emergence of high-levels of supposed integration while neglecting in-depth cooperation, and competing through the proposal of ever-higher goals with no regard for resource and environmental carrying capacities, leading to serious regional deprivation; and, third, the lack of unified identification standards, standardized statistical data, a clear centralized administrative organ, proven system of planning methods and practices, and authoritative urban agglomeration planning laws. On the one hand, these problems restrict the healthy and sustainable development of urban agglomerations, and on the other, provide a warning with regard to institutional mechanisms for the future selection and development of urban agglomerations. 


\section{Future priorities and direction of China's urban agglomeration selection and development}

\subsection{Being problem-oriented by focusing and reflecting on new problems exposed in the course of selecting and developing urban agglomerations in China}

(1) The strategic role of urban agglomerations in promoting urbanization in China has been overstated and overestimated. The Central Work Conference on Urbanization, Central Economic Work Conference, and national eleventh and twelfth five-year plans all mentioned urban agglomerations as the main spatial formations for accelerating and promoting the new type of urbanization. But in the process of selecting and determining the boundaries of urban agglomerations, governments at various levels placed too much emphasis on trying to include cities in urban agglomerations, with some even making entry to urban agglomerations into political projects, which led to an unprecedented number of cities being included in urban agglomerations, and urban agglomerations becoming unilaterally seen as one of the few means of promoting the new type of urbanization. Some even supported the theory that urban agglomerations were the only means of promoting the new type of urbanization. The general consensus was that cities in urban agglomerations would thrive, while those not in an urban agglomeration required help. This overestimation of the role of urban agglomerations seriously affected their healthy and natural development in China and seriously impacted the progress of the government's new type of urbanization.

(2) The constant expansion of the boundaries of urban agglomerations ran contrary to the original purpose of developing urban agglomerations. From a theoretical analysis, the expansion of the boundaries of urban agglomerations has undergone four expansions, from cities to metropolitan areas, from metropolitan areas to metropolitan regions, from metropolitan regions to urban agglomerations, and from urban agglomerations to megalopolises. Such artificial expansion is not something that happens overnight. With local governments and the media promoting them and some experts playing up their importance, many urban agglomerations constantly expanded. With a strong background of urban agglomeration growth being government-led in China, the spatial boundaries of urban agglomerations became a topic of interest for many provincial cities, and boundaries were expanded even without existing development. The result was a departure from the most basic standards for developing urban agglomerations and a loss of the positive effects of urban agglomerations brought about by their density and highly efficient growth (Fang et al., 2013a).

(3) The selection of urban agglomerations became subject to strong government leadership and departed from the basic standards governing their development. The development process of urban agglomerations is a gradual natural process, and it is a living entity with high levels of urban integration between cities. The construction of urban agglomerations does not depend on subjective "zoning," but rather, they are nurtured by market mechanisms and rely on cooperation between cities. As such, it is necessary to fully understand that their development is a long-term and arduous process. One cannot be too hasty and anxious for success. Instead, it is necessary to abide by the stage-based laws of development of urban agglomerations and gradually foster them so as to achieve sustainable development.

(4) The selection of urban agglomerations came to overly accommodate local interests, which affected China's overall strategic security. In the course of selecting urban agglom- 
erations, games and even deals took place between state and local governments. The state relied excessively on major function-oriented zones, and local enthusiasm was indomitable. Urban agglomerations became policy action areas of national urbanization and were expected to account for more than $75 \%$ of people moving to cities.

(5) Urban agglomerations and town clusters were often confused, but the two are essentially different. There are strict requirements and standards for urban agglomerations in terms of the size of their population and their economic output, whereas town clusters are not subject to these requirements. Instead, it only takes three or more clustered towns to establish economic and technological ties to form a town cluster. Looking at the structure of clusters, urban agglomerations include large, medium-sized, and small cities and towns, while town clusters only include small towns. In terms of their constituent numbers, as the radiation range of urban agglomerations expands, the number of urban agglomerations decreases, their boundaries become increasingly blurred, and as the regional economy integrates and urban and rural areas become more integrated as they develop, the number of town clusters increases. In terms of their competitiveness, urban agglomerations have strong national and international competitiveness and are the core growth poles of national economic development, whereas town clusters are only competitive locally. In terms of their relationship, urban agglomerations can contain several town clusters, but town clusters cannot contain urban agglomerations. In terms of their spatial distribution, urban agglomerations are located in some provinces, municipalities, and autonomous regions, whereas town clusters are found in every province, municipality, and autonomous region, including the Tibet Autonomous Region, which is not and will never be home to any urban agglomeration, but may contain a Lhasa-Shigatse town cluster. In terms of their development prospects, urban agglomerations and town clusters both become the main spatial forms for promoting the new type of urbanization, and both are equally important. As such, in the process of selecting urban agglomerations, it is necessary to distinguish between urban agglomerations and town clusters. The two should not be confused. Nevertheless, they are still regularly confused in official documents, academic research, and project designs.

(6) The argument that "urban agglomerations should no longer become groups of cities" misled the formation and development of urban agglomerations. According to the development standards for urban agglomerations, they should first be a group of cities. This is an undoubtable objective fact. If cities are not connected or concentrated, the most basic conditions for the development of an urban agglomeration do not exist. Only if there are enough cities can the foundations be laid for further urban integration. However, the argument that "urban agglomerations should no longer be groups of cities" misinterpreted the basic conditions for the development of urban agglomerations. If one agrees with this statement, then what should an urban agglomeration be? Only by first recognizing that urban agglomerations are groups of cities is it possible to discuss in greater depth how to promote industrial development, layout integration, integration of infrastructure construction, urban-rural development and planning integration, and other integration issues between each city within the group, and genuinely ensure the urban agglomeration becomes an economic community and a community with shared interests and a common destiny that benefits every city within its boundaries.

(7) Urban agglomerations have been in the spotlight as smog and other environmental 
problems intensify. Against a backdrop of China promoting an extensive mode of economic development for a long time in the past, on the one hand, urban agglomerations have become the most dynamic and promising areas for economic development now and in the future. But, on the other hand, urban agglomerations have also become highly sensitive areas where a series of environmental issues are concentrated and intensifying. According to incomplete statistics, industrial wastewater, emissions, and solid waste generation of urban agglomerations accounted for $67 \%$ of the totals for the whole of China. It can be seen that although China's urban agglomerations account for three-quarters of total national economic output, it also accounts for three-quarters of the country's output of pollution, and the smog of pollution that covers all the urban agglomerations on the eastern seaboard and in the northeast region fully reflects the increasingly prominent environmental problems (Fang et al., 2011).

\subsection{Focusing on promoting the new " $5+9+6$ " urban agglomeration spatial pattern}

In terms of the strategic positioning of urban agglomerations and dealing with problems associated with their selection and development, the selection of urban agglomerations in China in the future should be based on national functional-oriented zone planning, national urban system planning, and national urbanization planning. From the perspective of trying to nurture national new-type urbanization policy action zones, China should focus on forming a " $5+9+6$ " urban agglomeration spatial structure, consisting of five national-level, nine regional-level, and six local urban agglomerations (Fang, 2013b) (Figures 2 and 3).

The figures above show that 422 (63.94\% of the total in China) cities and towns are located in China's urban agglomerations, including four municipalities, 191 (66.32\%) prefecture-level cities, 231 (62.77\%) county-level cities, and 11,787 (60.73\%) small towns. In 2010, China's urban agglomeration contained $62.83 \%$ of the country's total population and accounted for $67.05 \%$ of the area of China's administrative districts of cities; $80.57 \%$ of national GDP; $59.88 \%$ of growth in China's primary industries, $95.29 \%$ of growth in its secondary industries, and $86.14 \%$ of growth in its tertiary industries; $76.87 \%$ of total private fixed-asset investment; and $87.24 \%$ of foreign capital actually utilized. All of this reflects the overall concentration of various factors of production taking place within urban agglomerations.

(1) Building five national-level urban agglomerations. The five national-level urban agglomerations are the Yangtze River Delta, Pearl River Delta, Beijing-Tianjin-Hebei, Middle Yangtze, and Chengdu-Chongqing urban agglomerations. These are all based around national core cities and have formed growth poles that drive national economic development and have global influence and competitiveness, and they will eventually develop into world-class urban agglomerations. Currently, national-level urban agglomerations account for $9.06 \%$ of China's total land space, $31.39 \%$ of its population, $35.15 \%$ of its construction land area, $43.38 \%$ of the urban population, $46.68 \%$ of GDP, $39.11 \%$ of total fixed investment, and $57.58 \%$ of foreign capital actually utilized (Tables 2 and 3).

(2) Building nine regional-level urban agglomerations. The nine regional-level urban agglomerations are the Harbin-Changchun, central and southern Liaoning, Shandong Peninsula, western Taiwan Straits, Central Plains, Guanzhong, Guangxi, Jianghuai, northern Tianshan Mountains urban agglomerations. These regional urban agglomerations are key urbanized areas for driving regional economic development. They are the second-tier urban agglomera- 
tions normally centered on one or more national central cities or regional central cities. In regions with strong resource and environmental carrying capacities, relatively complete urban systems, and regional central cities with a considerable radiation effect, the focus is on

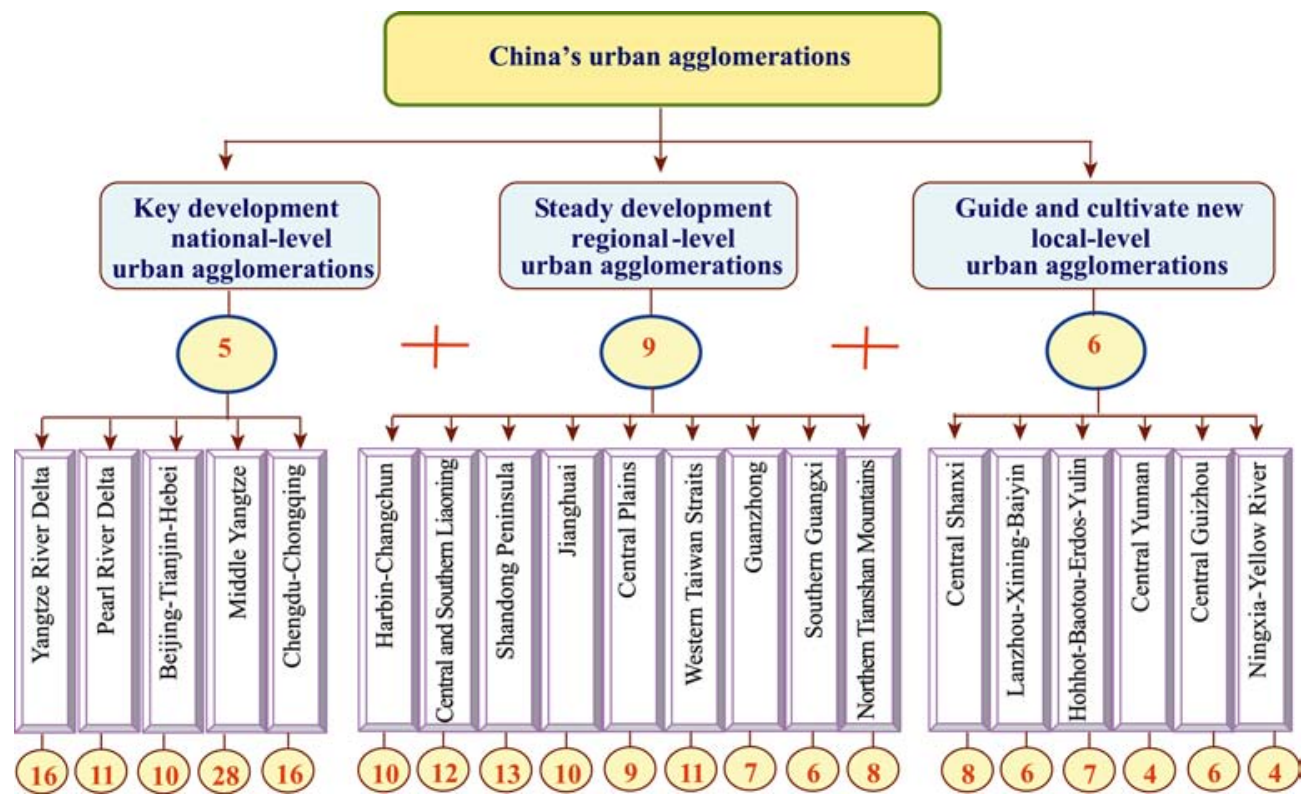

Figure 2 The framework of policy options for China's urban agglomerations

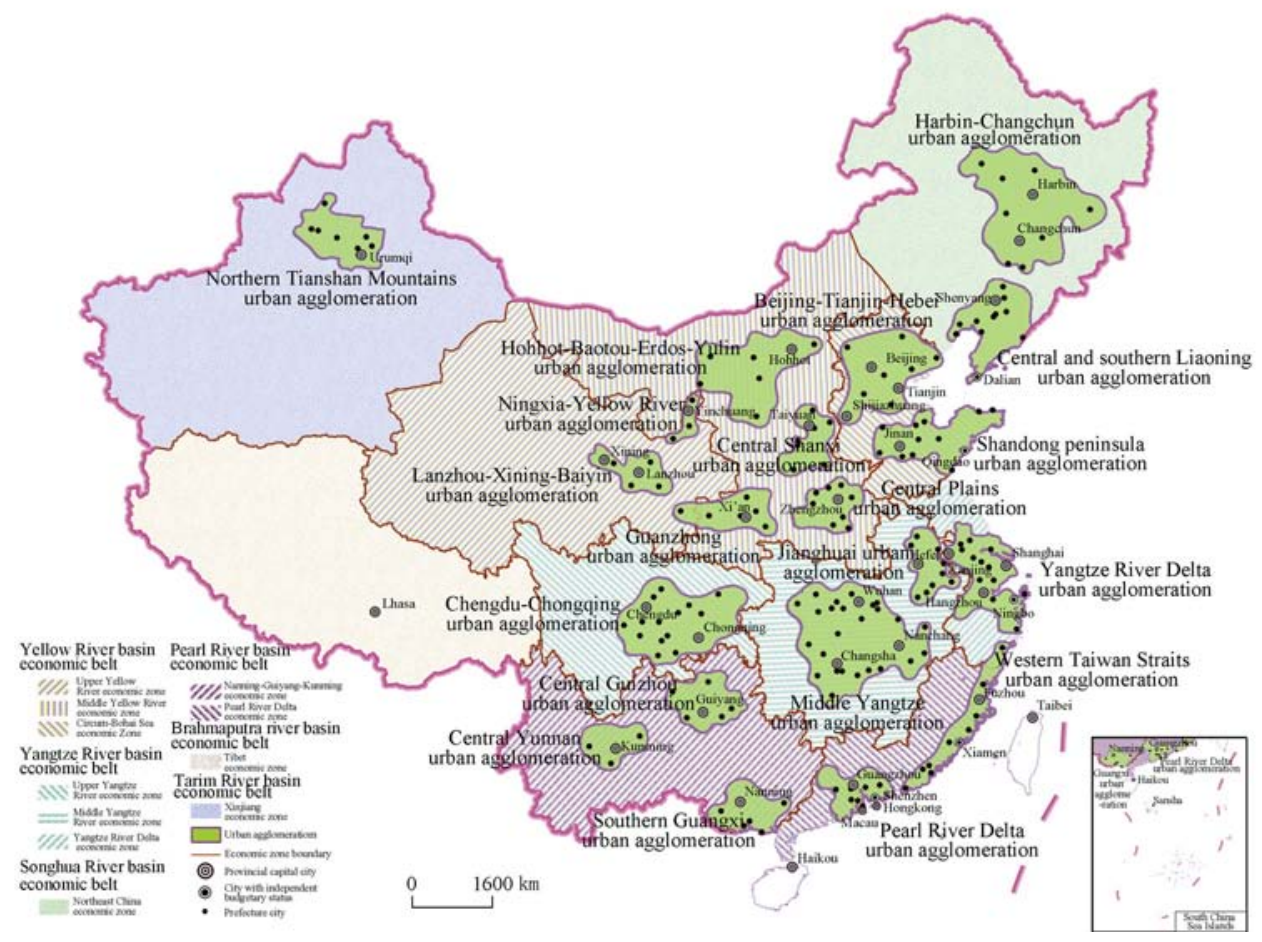

Figure 3 New spatial pattern of " $5+9+6$ " in the future construction of China's urban agglomerations 
Table 2 Comparison of key indicators of different levels of urban agglomerations in China (2010)

\begin{tabular}{|c|c|c|c|c|c|c|c|c|c|c|}
\hline $\begin{array}{c}\text { Urban } \\
\text { agglomeration } \\
\text { classification }\end{array}$ & $\begin{array}{l}\text { Total areac } \\
\left(\mathrm{km}^{2}\right)\end{array}$ & $\begin{array}{c}\text { Urban } \\
\text { construction } \\
\text { land area } \\
\left(\mathrm{km}^{2}\right)\end{array}$ & $\begin{array}{c}\text { Total } \\
\text { popula- } \\
\text { tion }\left(10^{4}\right)\end{array}$ & $\begin{array}{c}\text { Urban } \\
\text { popula- } \\
\text { tion }\left(10^{4}\right)\end{array}$ & $\begin{array}{c}\text { GDP } \\
\text { (current } \\
\text { rate, RMB } \\
10^{8} \text { ) }\end{array}$ & $\begin{array}{c}\text { Primary } \\
\text { industry } \\
\text { value } \\
\text { added } \\
\text { (RMB } 10^{8} \text {, }\end{array}$ & $\begin{array}{c}\text { Secondary } \\
\text { industry } \\
\text { value added } \\
\left.\text { (RMB } 10^{8}\right) \\
\end{array}$ & $\begin{array}{c}\text { Tertiary } \\
\text { industry } \\
\text { value added } \\
\left(\text { RMB } 10^{8}\right)\end{array}$ & $\begin{array}{c}\text { Total } \\
\text { fixed-asset } \\
\text { investment } \\
\text { (RMB } 10^{8} \text { ) }\end{array}$ & $\begin{array}{c}\text { Foreign } \\
\text { capital } \\
\text { actually } \\
\text { utilized } \\
\left(\mathrm{US} \$ 10^{8}\right) \\
\end{array}$ \\
\hline National-level & 869963 & 13989.2 & 42093.49 & 20147.8 & 203148.57 & 11667.49 & 99348.68 & 92134.05 & 108763 & 1101.2 \\
\hline Regional-level & 945039.6 & 10129.95 & 33081.11 & 12887.56 & 122389.18 & 10723.83 & 65673.95 & 45988.65 & 86718.5 & 514.85 \\
\hline Local-level & 663894 & 2538.74 & 9075.87 & 3009.62 & 26590.42 & 1881.84 & 13728.51 & 10979.64 & 18298.36 & 52.33 \\
\hline $\begin{array}{l}\text { Total China's } \\
\text { urban aggs. }\end{array}$ & 2478897 & 26657.89 & 84250.47 & 36044.98 & 352128.17 & 24273.18 & 3178751.14 & 149102.34 & 213779.87 & 1668.39 \\
\hline
\end{tabular}

Table 3 Percentages of key indicators for different levels of urban agglomerations in China to the national totals (2010)

\begin{tabular}{|c|c|c|c|c|c|c|c|c|c|c|c|}
\hline \multicolumn{2}{|c|}{$\begin{array}{c}\text { Urban agglomeration } \\
\text { classification }\end{array}$} & $\begin{array}{c}\text { Total } \\
\text { area } \\
\left(\mathrm{km}^{2}\right)\end{array}$ & $\begin{array}{c}\text { Urban } \\
\text { construc- } \\
\text { tion land } \\
\text { area } \\
\left(\mathrm{km}^{2}\right)\end{array}$ & $\begin{array}{c}\text { Total } \\
\text { popu- } \\
\text { lation } \\
\left(10^{4}\right)\end{array}$ & $\begin{array}{c}\text { Urban } \\
\text { popu- } \\
\text { lation } \\
\left(10^{4}\right)\end{array}$ & $\begin{array}{c}\text { GDP } \\
(\mathrm{RMB} \\
\left.10^{8}\right)\end{array}$ & $\begin{array}{c}\text { Primary } \\
\text { industry } \\
\text { value } \\
\text { added } \\
(\mathrm{RMB} \\
\left.10^{8}\right)\end{array}$ & $\begin{array}{c}\text { Secon- } \\
\text { dary } \\
\text { industry } \\
\text { value } \\
\text { added } \\
(\text { RMB } \\
\left.10^{8}\right) \\
\end{array}$ & $\begin{array}{c}\text { Tertiary } \\
\text { industry } \\
\text { value } \\
\text { added } \\
\text { (RMB } \\
10^{8} \text { ) }\end{array}$ & $\begin{array}{c}\text { Tertiary } \\
\text { industry } \\
\text { value } \\
\text { added } \\
(\mathrm{RMB} \\
\left.10^{8}\right)\end{array}$ & $\begin{array}{c}\text { Foreign } \\
\text { capital } \\
\text { actually } \\
\text { utilized } \\
\left(\mathrm{US} \$ 10^{8}\right)\end{array}$ \\
\hline \multirow{3}{*}{$\begin{array}{c}\text { Percentage } \\
\text { to national } \\
\text { totals of } \\
\text { urban aggs. }\end{array}$} & National-level & 35.09 & 52.48 & 49.96 & 55.90 & 57.69 & 48.07 & 55.58 & 61.79 & 50.88 & 66.00 \\
\hline & Regional-level & 38.12 & 38.00 & 39.27 & 35.75 & 34.76 & 44.18 & 36.74 & 30.84 & 40.56 & 30.86 \\
\hline & Local-level & 26.78 & 9.52 & 10.77 & 8.35 & 7.55 & 7.75 & 7.68 & 7.36 & 8.56 & 3.14 \\
\hline \multirow{3}{*}{$\begin{array}{c}\text { Percentage } \\
\text { to national } \\
\text { totals }\end{array}$} & National-level & 9.06 & 35.19 & 31.39 & 43.83 & 46.48 & 28.78 & 52.96 & 53.23 & 39.11 & 57.58 \\
\hline & Regional-level & 9.84 & 25.48 & 24.67 & 28.04 & 28.00 & 26.46 & 35.01 & 26.57 & 31.18 & 26.92 \\
\hline & Local-level & 6.92 & 6.39 & 6.77 & 6.55 & 6.08 & 4.64 & 7.32 & 6.34 & 6.58 & 2.74 \\
\hline
\end{tabular}

improving infrastructure, enhancing the functions of central cities, and promoting the division of labor, as well as actively fostering the formation of regional urban agglomerations. Regional urban agglomerations currently account for $9.84 \%$ of China's total land space, $24.67 \%$ of the country's population, $25.48 \%$ of its construction land area, $28.04 \%$ of its urban population, $31.8 \%$ of total fixed-asset investment, and $26.92 \%$ of foreign capital actually utilized.

(3) Fostering six new local-level urban agglomerations. The six new local-level clusters are the central Shanxi, Lanzhou-Xining-Yinchuan, Ningxia-Yellow River, Hohhot-BaotouErdos-Yulin, central Yunnan, and central Guizhou urban agglomerations. These urban agglomerations are concentrated in China's central and western regions and are the main development areas of each province, and they play an important role in the economic development of those provinces. However, these areas are still in the early stages of developing urban agglomerations, i.e. the stage of nurturing metropolitan areas, but it is expected that through hard work they will foster relatively small urban agglomerations. Therefore, regional metropolitan areas being nurtured today will guide the formation of new urban agglomerations in the future, as play is given to their important role in supporting provincial economic development and absorbing rural migrants. Local-level urban agglomerations currently account for $6.92 \%$ of China's total land space, $6.77 \%$ of the country's population, $6.39 \%$ of its construction land area, $6.55 \%$ of its urban population, $6.08 \%$ of GDP, $6.58 \%$ of total fixed-asset investment, and $2.74 \%$ foreign capital actually utilized. 


\subsection{Focusing on promoting the new type of urbanization in China based on clusters along the main axes}

The 20 urban agglomerations of the “ $5+9+6$ ” spatial structure will be used as core strategic nodes located along the five main urbanization axes, namely the coastal cities urbanization axis, Yangtze River urbanization axis, Eurasian land bridge urbanization axis, Harbin-Beijing-Guangzhou urbanization axis, and Baotou-Kunming urbanization axis, to form a new national macro-pattern of urbanization (Figures 4 and 5).

\subsection{Being guided by national strategic demands and continuing to deepen awareness of major scientific issues in the formation and development of urban agglomerations}

(1) Deepening research on resource and environmental effects of high-density urban agglomerations

In response to China's urban agglomerations having high-density clustering, rapid growth, heavy traffic, high-risk threats, low resource and environmental protection, low development, poor compactness, and low input and output efficiency, there is a need to strengthen research on the " $5+9+6$ " urban agglomeration spatial pattern by using RS and GIS technology and selecting the internal and external driving forces from natural, economic, and political factors affecting high-density clustering within urban agglomerations and researching the driving mechanisms, clustering and diffusion mechanisms, and weight-shift mechanisms against the backdrop of globalization, informationization, and new-type urbanization, and to reveal the combined effects of various driving forces in urban agglomeration formation, development, and expansion; to reveal urban agglomeration high-density clustering resource and environmental response mechanisms, the intensity of combined effects, and laws governing variation; and, using a computational simulation test, to calculate water, construction land, and environmental safeguard levels for high-density urban agglomerations, analyze the resource and environmental safeguard levels of high-density urban agglomerations with different carrying capacities, and calculate the size and strength of high-density urban agglomerations under different safeguard levels.

There is also a need to quantify and reveal the resource and environmental load capacities, safeguard potential, scenario response capabilities, and resource and environmental safeguard levels of high-density urban agglomerations; to establish, based on the calculated results of resource and environment thresholds and safeguard levels, a resource and environment response computational experiment system for high-density urban agglomerations, involving determining experiment variables, calculating multiple experimental scenarios, repeating experiment calculations, and making adjustments to produce a high-density urban agglomeration method and highly efficient growth model suited to resource and environmental capacities. All of this would help promote the healthy and sustainable development of urban agglomerations in China and provide a scientific decision-making basis for developing resource-saving, environmentally friendly, low-carbon, and ecological urban agglomerations.

(2) Scientifically determining the resource and environmental carrying capacities of high-density urban agglomerations 


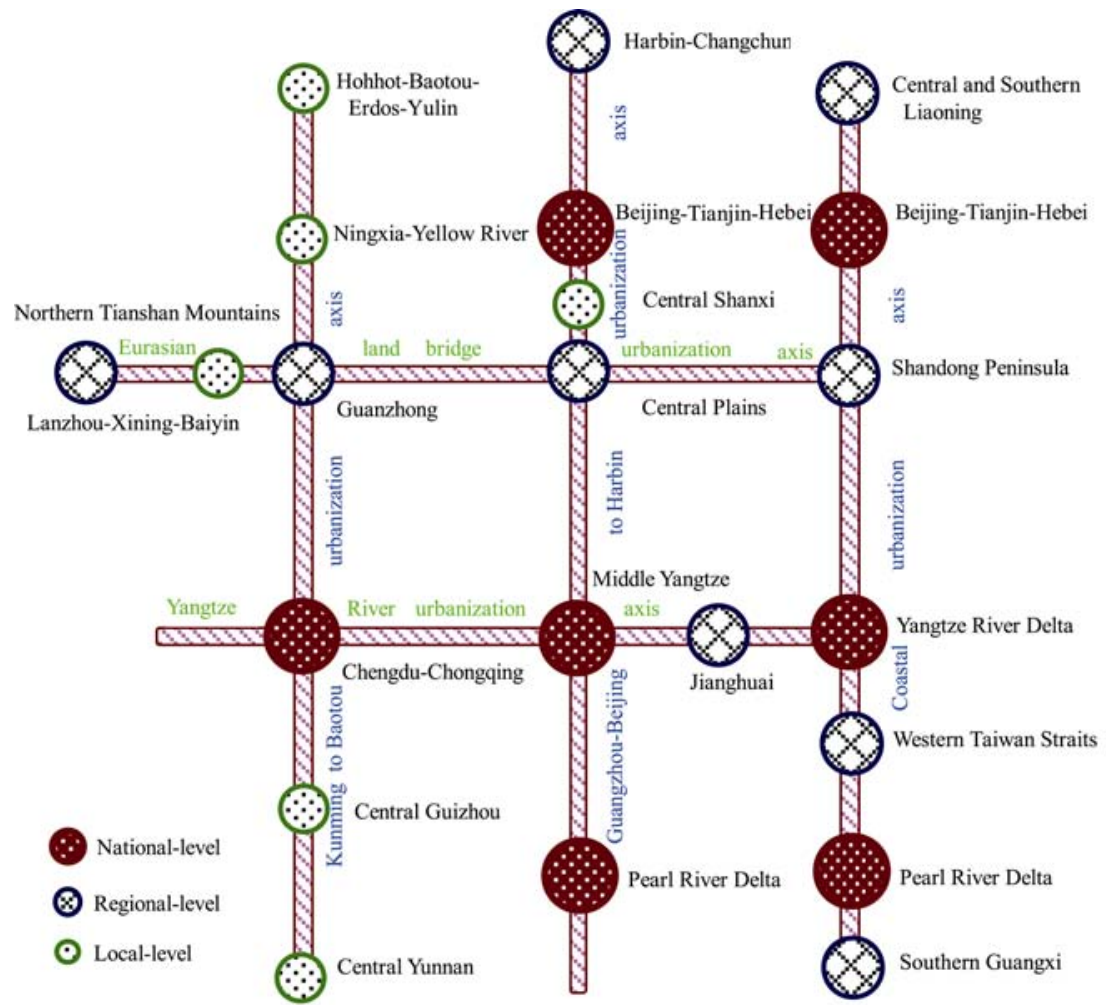

Figure 4 Framework of the spatial pattern of new-type urbanization development based on "clusters along the axes"

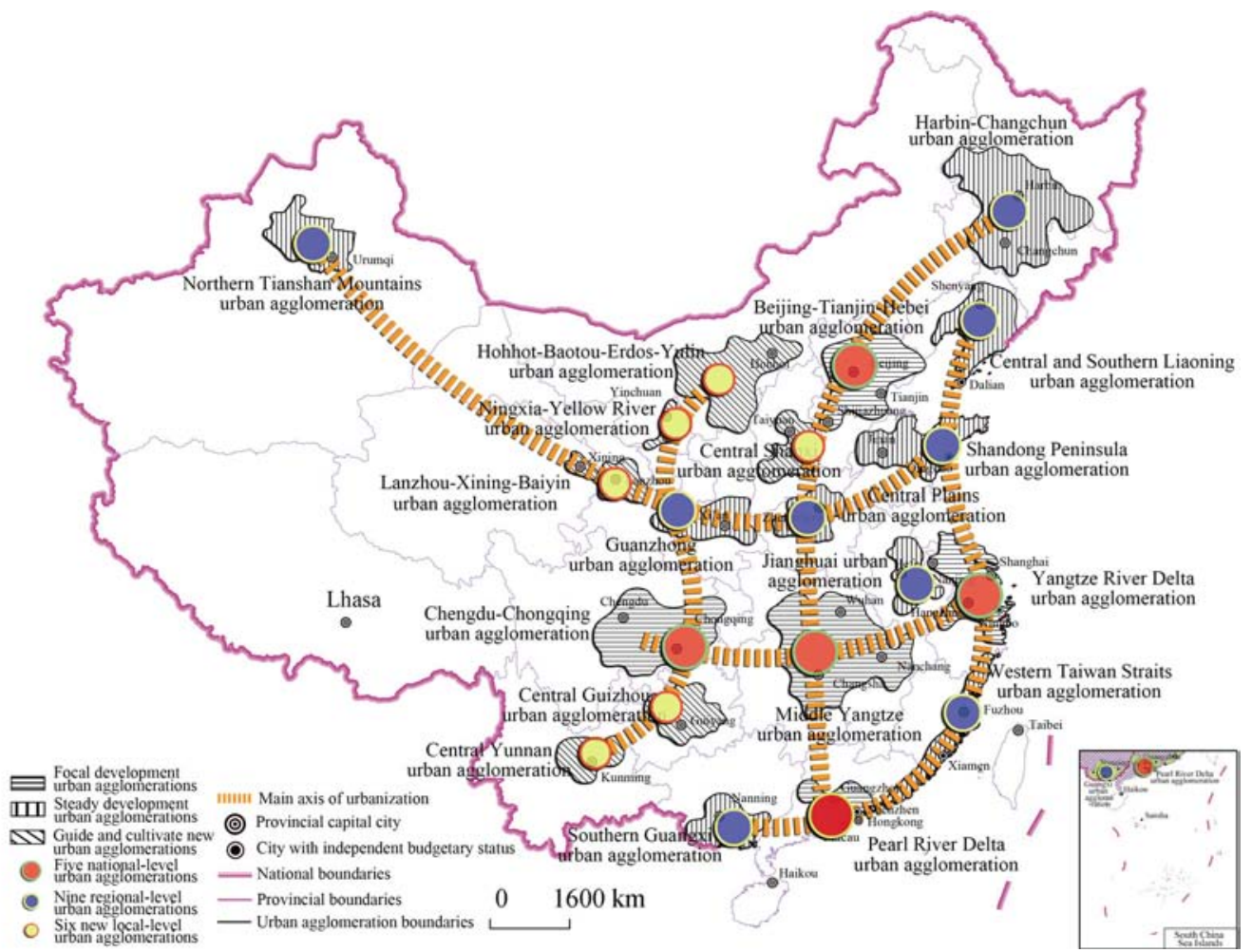

Figure 5 The new spatial pattern of China's urbanization based on “clusters along the axes" 
From the perspective of natural factors, it is necessary to focus on the impact of ecological, water, land, and environmental carrying capacities and analyze the effect and intensity of ecological, water, land, and environmental constraint mechanisms on high-density urban agglomerations. Using an expert group decision making model and fuzzy membership function model supported by entropy techniques from information theory, by calculating an urban agglomeration index, resource support index, environmental capacity index, integrated capability index, and cultural evolution index, it is possible to calculate the resource and environmental carrying capacity status of high-density clusters and analyze the stress level of resources and the environment on high-density urban agglomerations. It is also possible to use "emergy" (embodied energy) analysis, ecological footprint analysis, and ecosystem services value assessment techniques to carry out assessments of the value of ecosystem services of urban agglomeration areas and to evaluate the resource security and ecological and environmental security of high-density urban agglomerations by calculating changes in the per capita ecological footprint, per capita ecological carrying capacity, and per capita ecological deficit. In accordance with the "wooden barrel theory," on the basis of an urban agglomeration resource and environmental carrying capacity pressure and saturation model and integrated construction urban agglomeration resource and environment load capacity model, it is possible to determine the resource and environmental carrying capacity of high-density urban agglomerations, and to carry out a comparison of the overall resource and environment guaranteed population scale and economic scale calculated for a certain period with the population scale and economic development scale of urban agglomerations to determine the population and economic scale of the carrying capacity for urban agglomerations in different periods of time, propose the resource and environmental thresholds for high-density urban agglomerations, and thus provide a scientific basis for urban agglomerations to achieve sustainable development. Using a scenario analysis model to design various scenarios involving the interaction and impact of water, land, environment, and other resource and environmental factors, it is possible to analyze the impact of each scenario on the orientation, size, and intensity of high-density urban agglomeration; to analyze the effect of interactions of different resource and environmental factors in high-density urban agglomerations on the hierarchical structure, functional structure, and spatial structure of urban agglomerations; and then to analyze the prospects of resource and environmental safeguards for high-density urban agglomerations, establish a resource and environmental warning indicator and signaling system, as well as an early warning response system, and propose a maximum limit on the size of high-density urban agglomerations.

(3) The management system and government coordination mechanisms for forming and developing innovative urban agglomerations

The history of urban agglomeration development in China shows that the fundamental reason for being difficult to form a pattern of economic coordinated development is the lack of unified, coordinated, and effective competition rules and the lack of authoritative institutions to develop and implement such rules. Urban sociologist Lewis Mumford has stated that if better economic development is wanted it is necessary to set up regional authorities with legal credentials and planning and investment authority, and provide regional coordinating bodies in the areas of powers, duties, and funding to guarantee efficient operation. To this end, in order to ensure coordination between urban agglomerations, it is necessary to establish effective regional coordinating bodies. 
First, it is necessary to clarify the roles of national centralized management authorities, set up national-level urban agglomeration coordinated development management committees, pay attention to overall planning and governance work related to national economic development, overcome local protectionism, establish urban agglomeration common markets, set up urban agglomeration benefit-sharing mechanisms, and promote an equal governance structure and coordination mechanisms that are mutually beneficial, mutually restraining, and complementary. Second, it is necessary to clarify the roles of local centralized management authorities and establish local-level urban agglomeration coordinated development management committees. Third, it is necessary to set up inter-city industry coordinating bodies that can deal with the public in official and semi-official capacities, and thereby form a new public management model with various types of interest groups, multilateral forces participating, harmonious government and non-government organizations, and that reflects the will of all sectors of society. Fourth, it is necessary to advocate polycentric governance and establish horizontal benefit-sharing mechanisms and benefit compensation mechanisms (Fang, 2007).

(4) Researching the establishment of urban agglomeration public finance and public finance reserve systems

With regard to urban agglomerations with urban-rural integration and densely populated and closely linked cities, public finance is an important guarantee for resolving resource allocation and spatial layout issues within urban agglomerations. The main roles of public finance in the implementation of urban agglomeration planning are as follows: to directly invest in urban agglomeration construction, raise funds for the construction and development of urban agglomerations, and regulate construction activities and investment in urban agglomerations. To this end, it is necessary to establish urban agglomeration public finance mechanisms and professional public finance committees to coordinate local fiscal policies and exercise regional financial integration powers. At the same time, it will be necessary to establish an urban agglomeration public finance reserve system and jointly develop and share regional public goods. A proportional share of funds for developing regional public goods would be required, for example to construct public transport, whereby the central government would pay a share, regional funding (given that all parties would benefit from the public transport) would pay a share, and local governments of places the transport passes through (as they would stand to benefit slightly more) would pay a share. The cost of construction of regional information networks and information analysis and dissemination should be borne by regional common finances. The source of regional common finances for urban agglomerations could be similar to the financing of the EU. First of all, income whose distribution may cause a conflict of interests is shared. For example, revenue from a regional transportation network can be distributed based on the proportion invested, while a portion of revenue is placed under regional financial ownership in order to avoid the issue of duplicate construction due to transport network revenue benefits. Alternatively, an appropriate commission or certain proportion of VAT revenue based on local GDP could be given to regional coordinated development management committee.

(5) Researching the formulation of technical specifications for urban agglomeration planning and criteria for defining their boundaries

Urban agglomeration planning provides guidelines for achieving their sustainable development. Good planning is the government's greatest wealth and capital, whereas bad plan- 
ning is the worst case of government waste. Urban agglomeration planning does not simply involve "summarizing" the plans of individual constituent cities. Rather, it takes the regional-level urban agglomeration system as its starting point and makes strategic arrangements and adjustments for the overall development of the cluster. In recent years, as urban agglomerations have thrived, the National Development and Reform Commission, the Ministry of Housing and Urban-Rural Development, and governments of provinces and autonomous regions have organized to formulate urban agglomeration plans at different levels, which have played an important role in guiding the development of cities within urban agglomeration areas. Nevertheless, urban agglomeration planning has not been part of the statutory spatial planning system, and a lack of uniform urban agglomeration planning standards or a long-term stable institutional framework for long-term follow-up supervision has resulted in a lack of continuity in urban agglomeration planning, which has itself resulted in vastly different urban agglomeration planning content, with disconnected timings, urban and rural planning, and decreasing planning guidance, making it difficult to implement plans to the letter. As such, the proposal and early introduction of urban agglomeration planning technical guidelines and technical regulations would clarify procedures for urban agglomeration planning proposals; feasibility studies; the preparation, review, and approval of plans; public announcements; and modifications. The formulation of technical guidelines and technical regulations has put urban agglomeration planning in China onto a scientific track. At the same time as scientifically formulating urban agglomeration planning, it is recommended that scientific and technical methods are adopted to determine and propose technical methods and standards for determining the spatial boundaries of urban agglomerations in order to avoid existing cities from being swallowed by them arbitrarily or for political motives, as well as to avoid urban agglomerations appearing out of nowhere and giving rise to redundant construction of urban agglomerations that is worse than redundant project construction.

\section{References}

Chen Hao, Lu Lin, Zheng Shanting, 2011a. The spatial network structure of the tourism destinations in urban agglomerations based on tourist flow: A case study of the Pearl River Delta. Acta Geographica Sinica, 66(2): 257-266. (in Chinese)

Chen Hao, Lu Lin, Zheng Shanting, 2011b. Evolution of travel spatial patterns in the Pearl River Delta urban agglomeration. Acta Geographica Sinica, 66(10): 1427-1437. (in Chinese)

Fang Chuanglin, 2007. On Regional Planning and Space Governance. Beijing: The Commercial Press, $234-239$. (in Chinese)

Fang Chuanglin, 2009. Progress and basic judgments in identifying the spatial extent of urban agglomeration. Urban Planning Forum, (3): 1-5. (in Chinese)

Fang Chuanglin, 2010. Development status quo and key points of construction of urban agglomerations in west regions of China. Arid Land Geography, 33(5): 667-675. (in Chinese)

Fang Chuanglin, 2011. New structure and new trend of formation and development of urban agglomerations in China. Scientia Geographica Sinica, 31(9): 1025-1035. (in Chinese)

Fang Chuanglin, 2012. Policy implication process and prospect of Chinese urban agglomerations formation and development. Scientia Geographica Sinica, 32(3): 257-264. (in Chinese)

Fang Chuanglin, 2013a. Scientific definition for the middle Yangtze urban agglomeration. China National Conditions and Strength, (10): 52-53. (in Chinese)

Fang Chuanglin, 2013b. Adjusting urban development policy, optimizing urban development pattern. China Economic Times, 08-12. (in Chinese)

Fang Chuanglin, Guan Xingliang, 2011. Integrated measurement and spatial differentiation of the input-output efficiency of Chinese urban agglomeration. Acta Geographica Sinica, 66(8): 1011-1022. (in Chinese) 
Fang Chuanglin, Lin Xueqin, 2010. Ecological conditions diagnostic of spatial expansion in Wuhan urban agglomeration. Resources and Environment in the Yangtze Basin, 19(10): 1211-1218. (in Chinese)

Fang Chuanglin, Liu Xiaoli, 2010. Comprehensive measurement of carrying degrees of resources and environment of the urban agglomeration located in central China. Chinese Geographical Science, 20(3): 281-288.

Fang Chuanglin, Qi Weifeng, Song Jitao, 2008. Comprehensive measurement analysis of the compactness of Chinese urban agglomeration. Acta Geographica Sinica, 63(10): 1011-1021. (in Chinese)

Fang Chuanglin, Song Jitao, Lin Xueqin, 2010. Theory and Practice of China's Sustainable Urbanization. Beijing: Science Press, 56-89. (in Chinese)

Fang Chuanglin, Song Jitao, Zhang Qiang et al., 2005. The formation, development and spatial heterogeneity patterns for the structures system of urban agglomerations. Acta Geographica Sinica, 60(5): 827-840. (in Chinese)

Fang Chuanglin, Yao Shimou, Liu Shenghe et al., 2011. Report on Urban Agglomeration Development in China. Beijing: Science Press, 25-33. (in Chinese)

Fang Chuanglin, Zhang Jian, 2011. Urban agglomerations formation and development in China: Policy guarantee mechanism, countermeasures and suggestions. China Population Resources and Environment, 21(10): 107-114. (in Chinese)

Gu Chaolin, 1991. A preliminary study of Chinese urban economic zoning. Acta Geographica Sinica, 46(2): 129-141. (in Chinese)

Guan Xingliang, Fang Chuanglin, Zhou Min et al., 2012. Spatial and temporal characteristics of spatial expansion of urban land in Wuhan urban agglomeration. Journal of Natural Resources, 27(9): 1447-1459. (in Chinese)

Kuang Wenhui, Liu Jiyuan, Lu Dengsheng, 2011. Beijing-Tianjin-Tangshan urban agglomeration impervious surface growth and the environmental effects on water. Acta Geographica Sinica, 66(11): 1486-1496. (in Chinese)

Lin Xueqin, Fang Chuanglin, 2010. Research on the eco-environment effect of industrial development in city group: A case of Wuhan city group. Geographical Research, 29(12): 2233-2243. (in Chinese)

Liu Hui, Shen Yuming, Liu Kun, 2013. The financial services industry development level and spatial pattern of urban agglomeration in China. Acta Geographica Sinica, 68(2): 186-198. (in Chinese)

Ma Xiaodong, Ma Ronghua, Xu Jiangang, 2004. Spatial structure of cities and towns with ESDA-GIS framework. Acta Geographica Sinica, 59(6): 1048-1057. (in Chinese)

Song Jitao, Fang Chuanglin, Song Dunjiang, 2006. Stability analysis of the spatial structure of Chinese urban agglomeration. Acta Geographica Sinica, 61(12): 1311-1325. (in Chinese)

Sun Fenghua, Wei Xiao, Liu Yuqiao, 2008. Core competitiveness of the logistics industry in the Shandong Peninsula urban agglomeration. Acta Geographica Sinica, 63(10): 1108-1118. (in Chinese)

Wang Jing, Fang Chuanglin, 2011. New-type driving forces of urban agglomerations development in China. Geographical Research, 30(2): 335-347. (in Chinese)

Wang Kaiyong, Chen Tian, 2008. The classification and analysis of areal topology in extended metropolitan area of Pearl River Delta. Acta Geographica Sinica, 63(8): 820-828. (in Chinese)

Wang Li, Deng Yu, Niu Wenyuan, 2013. The definition and identification of urban agglomerations. Acta Geographica Sinica, 68(8): 1059-1070. (in Chinese)

Wang Zhixian, Yu Xiaogan, Xu Kefeng, 2005. Sustainable development trends and countermeasures in the Yangtze River Delta. Acta Geographica Sinica, 60(3): 381-391. (in Chinese)

Xiong Ying, Li Jingzhi, Jiang Dingling, 2013. Optimized decision-making of water resources supply and demand system in Changsha-Zhuzhou-Xiangtan urban agglomeration based on the analog simulation. Acta Geographica Sinica, 68(9): 1225-1239. (in Chinese)

Xue Fengxuan, Yang Chun, 1997. The transborder economic region of Hong Kong-Shenzhen. Acta Geographica Sinica, 52(Suppl.): 16-27. (in Chinese)

Yao Shimou, Chen Shuang, 1998. Trends in urban spatial evolution in the Yangtze River Delta. Acta Geographica Sinica, 53(S): 1-10. (in Chinese)

Yao Shimou, Chen Zhenguang, Zhu Yingming et al., 2006. Urban Agglomerations of China. Hefei: University of Science and Technology of China Press, 5-7. (in Chinese)

Zhang Qian, Hu Yunfeng, Liu Jiyuan, 2011. Identification of urban clusters in China based on assessment of transportation accessibility and socio-economic indicators. Acta Geographica Sinica, 66(6): 761-770. (in Chinese)

Zhou Yixing, Zhang Li, 2003. China's urban economic region in the open context. Acta Geographica Sinica, 58(2): 271-284. (in Chinese) 